\title{
Comparative Study of Antioxidant Activity of Ethanol and Aqueous Extracts of Different Parts of Nyctanthes arbor-tristis Linn.
}

\author{
Saraswati Patel and Mamta Gokhale* \\ Department of Botany and Microbiology, St. Aloysius College (autonomous), Jabalpur-M.P., INDIA.
}

\begin{abstract}
Background: Antioxidants play a major role in curing degenerative disease. In present time many synthetic antioxidants are commonly used but due to their toxic and carcinogenic effects, their use has been restricted. So the search for natural antioxidants is important. Studies on natural compounds is of interest due to their satisfactory health benefits with low toxicity. Objective: The antioxidant activity of ethanol and aqueous extract of shoot, seed and leaf of an important medicinal tree Nyctanthes arbor-trist is (Harsingar) were evaluated by DPPH scavenging antioxidant assays. Materials and Methods: Different concentrations 25,50,75, 100\% of the aqueous and ethanol extracts were prepared with standard solutions (ascorbic acid 0.01, 0.03, 0.05, 0.07, 0.09, $0.1 \mathrm{mg} / \mathrm{ml}$ ). To $1.5 \mathrm{ml}$ solution of DPPH $(0.1 \mathrm{mM}), 0.5 \mathrm{ml}$ of various concentrations of the extract and standard were added. Results: In the present study a comparative evaluation of antioxidant activity of seed, shoot and leaf of Nyctanthes arbor-tristis
\end{abstract}

Linn was performed for their aqueous and ethanol extracts. Ethanol and aqueous extracts of shoot revealed more antioxidant activity then seed and leaf. Conclusion: All aerial parts of Nyctanthes arbor-trist is Linn possess antioxidant activity. The plant may be functioned out for its anticancerous properties in future.

Key words: Antioxidant activity, Aqueous extract, DPPH assay, Ethanol extracts, Nyctanthes arbor-tristis Linn

Correspondence:

Dr. (Mrs.) Mamta Gokhale, Department of Botany \& Microbiology, St. Aloysius College (autonomous), Jabalpur-M.P., INDIA.

E-mail: mamtashrirang@gmail.com

DOI: $10.5530 / p j .2016 .2 .3$

\section{INTRODUCTION}

Antioxidants are vital substances which possess the ability to protect the body from damage caused by free radical induced oxidative stress. Free radicals are highly reactive molecules containing one or more unpaired electron; they donate or take electron from other molecule in an attempt to pair their electron and generate a stable species. ${ }^{1}$ Antioxidants are both natural and synthetic compounds able to scavenge free radicals and inhibit oxidation processes. ${ }^{2}$ Many synthetic antioxidants such as butylatid hydroxyl anisole (BHA) and butylatid hydroxyl toluene (BHT) are very effective and used for industrial processing but they possess some side effect and toxic properties to human health therefore, there is an increasing interest in natural antioxidants, eg. Polyphenols, present in medicinal and dietary plants. ${ }^{3}$ Antioxidants play an important role in defending the body against free radical damage.

Epidemiological studies specify that intake of fruits and vegetables have the ability to inhibit the damaging behavior of free radicals in the human body. ${ }^{4}$ There were many plants other than those taken by human being to fulfill their food demand possesses important medicinal properties remain undiscovered. Nyctanthes arbor-tristis Linn is native to India one of the most useful traditional medicinal plants. It is a night flowering tree of family Oleaceae, it is well known in india and its neighbouring countries as one of the most versatile medicinal plant having a wide spectrum of biological activities, it is widely cultivated in tropical and subtropical regions all over the world. The secondary metabolite such as alkaloids, flavonoids, coumarins and steroids have been shown to possess antioxidant and anticancer activity in both in vivo and in vitro model. ${ }^{5-7}$ Recent studies have been shown that the leaves and stem of $N$. arbor-tristis possesses potential source of natural antioxidant. ${ }^{8}$ The antioxidant activity of phenolic compound is mainly due to their redox properties, which can play an important role in absorbing and neutralizing free radicals. ${ }^{9}$ In present study a comparative approach has been made to analyse the antioxidant properties of shoot, leaf and seeds of N. arbor-tristis.

\section{MATERIALS AND METHODS}

\section{Phytochemical analysis}

Phytochemical analysis of different parts of N. arbor-trist is was carried out applying various phytochemical tests. ${ }^{10,11}$

\section{Test for anthraquinone}

$0.5 \mathrm{ml}$ of the extract was boiled with $1 \mathrm{ml}$ of sulphuric acid and filtered while hot. The filtrate was shaken with $1 \mathrm{ml}$ of chloroform. The chloroform layer was pipetted out another test tube and $1 \mathrm{ml}$ of dilute ammonia was added. The resulting solution was observed for color change.

\section{Test for terpenoids}

To $0.5 \mathrm{ml}$ each of the extract was added $2 \mathrm{ml}$ of chloroform. Concentrated sulphuric acid $(3 \mathrm{ml})$ was carefully added to form a layer. A reddish brown coloration of the interface indicates presence of terpenoides.

\section{Test for flavonoids}

Diluted ammonia $(2 \mathrm{ml})$ was added to a portion of an aqueous filtrate of the extract. Concentrated sulphuric acid $(2 \mathrm{ml})$ was added. Yellow coloration that disappears on standing indicates the presence of flavonoids.

\section{Plant material}

Fresh leaf, shoot and seed of $N$. arbor-tristis were obtained from reserve forest area of Gwarighat. The sample was thoroughly rinsed and air dried. They were kept in hot air oven on $150^{\circ} \mathrm{C}$ for 4 hours for drying. The dried plant material was grind to fine powder.

\section{Preparation of extracts}

To prepare ethanol extractof shoot, leaf and seed of N. arbor-tristis, 2.5 $\mathrm{g}$ of each plant sample was soaked in $25 \mathrm{ml}$. ethanol, and kept in orbital shaker (sonar) on $150 \mathrm{rpm}$ for 2 days for extraction. Plant parts (leaf, shoot, and seed) each of $2.5 \mathrm{~g}$ were boiled on $100^{\circ} \mathrm{C}$ in $50 \mathrm{ml}$ water for 20 minutes. The extracts were filtered through what men filter paper and filtrate were used for antioxidant activity. 


\section{Chemicals and reagents}

Chemical such as 2, 2-Diphenyl-1-picryhydrazyl (DPPH) procured from HiMedia laborites Pvt. Ltd. (Mumbai-India), L-Ascorbic Acid procured from Sisco Research laborites Pvt. Ltd. (Mumbai-India).

\section{Spectrophotometric measurements}

Spectrophotometric measurements were performed by uv-visible double beam spectrophotometer (EI 2375) on wavelength $514 \mathrm{~nm}$.

\section{Determination of antioxidant activity-DPPH radical scavenging activity}

The DPPH radical scavenging activity of standard (ascorbic acid) and sample were determined by applying the method described by Mensor et al. $2001^{12}$ with some modifications. Different concentrations 25, 50, 75, $100 \%$ of the aqueous and ethanol extracts and standard solution (ascorbic acid $0.01,0.03,0.05,0.07,0.09,0.1 \mathrm{mg} / \mathrm{ml}$ ) were prepared. To $1.5 \mathrm{ml}$ solution of DPPH $(0.1 \mathrm{mM}), 0.5 \mathrm{ml}$ of various concentration of the extract was added. Then the mixture was shaken vigorously and allowed to stand for $30 \mathrm{~min}$ at room temperature. The absorbance of resulting solution was measured at $514 \mathrm{~nm}$ with uv visible spectrophotometer. Inhibition of free radical DPPH in percent antioxidant activity (\%AA) was calculated in following way-

$$
A A \%=(\text { Abs control }- \text { Abs sample }) / \text { Abs control } \times 100
$$

\section{Abs-Absorbance}

Antioxidant activity of two extracts of shoot, leaf and seeds were compared statistically by calculating \pm standard deviation. Enhancement in the antioxidant activity, with increasing concentrations of extract were calculated by fold enhancement in comparison to lowest concentration (25\%) and expressed in result section.

\section{RESULTS}

\section{Phytochemical analysis of leaf, shoot and seed of aqueous extract of N. arbor-tristis}

Test for anthraquinone: Color change was observed when sample were tested for anthraquinone test which was an indication of presence of anthraquinone in samples. Least color intensity of anthraquinone was found in seed extract of $N$. arbor-tristis, whereas in leaf extract color intensity was slightly more than seed extract. In shoot extract maximum intensity of color change was observed, this is an indication of presence of high anthraquinone (Table 1, Figure 1).

Test for flavonoids: Yellow color was observed which showed the presence of flavonoids in all samples. It was found maximum in leaf extract of N. arbor-tristis (Table 1, Figure 2).

Test for terpenoids: Reddish brown coloration of the interface in all samples indicates presence of terpenoids. Minimum color intensity was found in seed extract and maximum in leaf and shoot extracts of $N$. arbor-tristis. It was clear from above observations that shoot and leaf contain more terpenoids than seed (Table 1, Figure 3).

Antioxidant activity was analyzed for shoot, leaf and seeds of N. arbor-tristis. The free radicals scavenging activity of different parts of N. arbor-tristis was studied by their ability to reduce the DPPH, stable free radicals.

Table 1: Phytochemical analysis of aqueous extract of shoot,
leaf and seed of $\boldsymbol{N}$. arbor- tristis
\begin{tabular}{ccccc}
\hline Plant parts & Anthraquinone & Flavanoids & Terpenoids \\
\hline Seed & + & ++ & + \\
Leaf & ++ & +++ & +++ \\
Shoot & +++ & + & ++ \\
\hline
\end{tabular}

Table 2: Antioxidant activity of ethanol and aqueous extract of seed, shoot and leaf of $\boldsymbol{N}$. arbor-tristis

\begin{tabular}{ccccc}
\hline Plant extracts & $\begin{array}{c}\text { Concentrations } \\
\text { (\%) }\end{array}$ & \multicolumn{3}{c}{ Plant organs } \\
\cline { 3 - 5 } & 25 & $34 \pm 0.05$ & $40 \pm 0.04$ & $47 \pm 0.03$ \\
\hline Ethanol (\%) & 50 & $81 \pm 0.00$ & $58 \pm 0.07$ & $61 \pm 0.03$ \\
& 75 & $84 \pm 0.02$ & $82 \pm 0.05$ & $87 \pm 0.00$ \\
& 100 & $91 \pm 0.01$ & $88 \pm 0.04$ & $89 \pm 0.03$ \\
Aqueous (\%) & 25 & $40 \pm 0.02$ & $12 \pm 0.44$ & $24 \pm 0.02$ \\
& 50 & $39 \pm 0.4$ & $15 \pm 0.07$ & $32 \pm 0.01$ \\
& 75 & $47 \pm 0.32$ & $55 \pm 0.02$ & $45 \pm 0.04$ \\
& 100 & $47 \pm 0.5$ & $78 \pm 0.02$ & $48 \pm 0.01$ \\
\hline
\end{tabular}

Comparison of two extracts (aqueous and ethanol) of shoot, seed and leaf were made to study their antioxidant activity.

Antioxidant activity of both extracts was analyzed by applying different concentrations $(25,50,75 \& 100 \%)$. Antioxidant activity increased with increasing concentration of both plant extract. Ethanol extract of shoot revealed more antioxidant activity then seed and leaf (Table 2) (DPPH scavenging activity in shoot was ranging from $34(25 \%)$ to $91(100 \%)$. The enhancement of antioxidant activity was 57 folds in shoot ethanol extract (Figure 4), whereas in leaf it was ranging from 47 to 88 folds (Figure 5), and in seed scavenging activity was ranging from 470.03 (in $25 \%$ ) to 890.03 (in 100\%) 42 folds (Figure 6), although the maximum antioxidant activity was recorded on lowest concentration (25\%) of seed ethanol extract (Graph 1).

In aqueous extract the leaf extract exhibited more antioxidant activity then shoot and seed. DPPH scavenging activity in leaf ranging from 12 The enhancement of antioxidant activity\% was 66 folds in leaf extractwhereas in shoot it was ranging from 40 Aqueous extract of seed has the minimum antioxidant activity occurred only 24 folds. 24 .

\section{DISCUSSION}

The importance of medicinal plant is due the presence of phytochemicals present inside them. Phytochemicals are naturally occurring substances of medicinal plants that have defense mechanism and protect the plant from various diseases. Phytochemicals are primary and secondary compounds. Chlorophyll, proteins and common sugars are included in primary constituents and secondary compounds have terpenoid, alkaloids and phenolic compounds. In the present study phytochemical analysis has been made to examine the presence of terpenoids, flavonoids and anthraquinone in the aqueous extract of shoot, leaf and seed of $N$. arbor tristis, out of them terpenoids and flavonoids were found maximum in the aqueous extract of leaf. ${ }^{13}$ Also reported the same observation in the methanolic extract of leaf of N. arbor-tristis. Presence of flavonoids in Terminalia bellerica (leaf) and terpenoids in Xanthium strumarium (leaf) in the Ricinus communis (leaf) are reported earlier. ${ }^{14}$

Antioxidant activity is a measure of anticancerous properties of any plants. Recently the antioxidant nature of many plants has beendiscussed. Researchers have got the data about antioxidant activity of many mysterious plants. ${ }^{15,16} \mathrm{~N}$. arbor-tristis is a well-known medicinal plant from ancient time, leaves of this plant was used to cure fever, arthritis, sciatica. ${ }^{17}$ Different plant part hasbeen used to cure many diseases similarly, powder of seeds is used to cure piles and skin disease. ${ }^{18}$ But the antioxidant nature of this plant remains undiscovered. There are very few reports regarding the antioxidant activity of different parts of this plant. ${ }^{19}$ Reported that n-butenol extract of flower of $N$. arbor-tristis exhibited antioxidant activity. Ethanol bark extract of $N$. arbor-tristis was also observed to possess antioxidant activity. ${ }^{18}$ Present investigation is a comparative analysis of antioxidant activity of three parts with their 


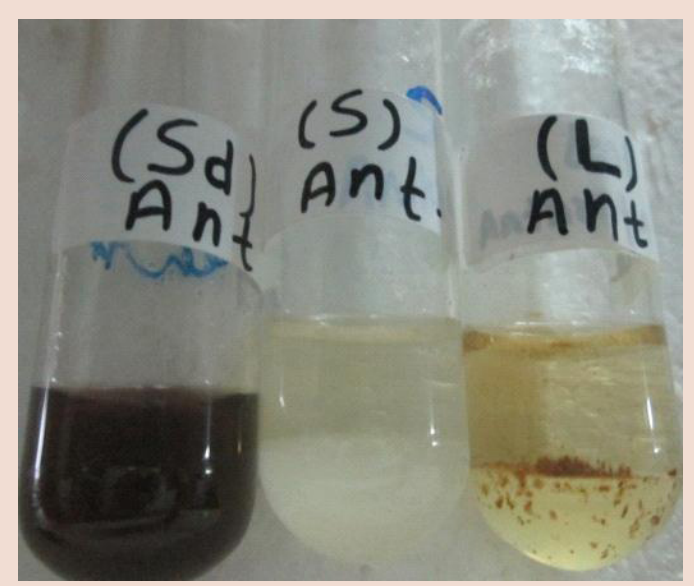

Figure 1: Anthraquinone analysis of aqueous extract of shoot, leaf and seed of N. arbor-tristis

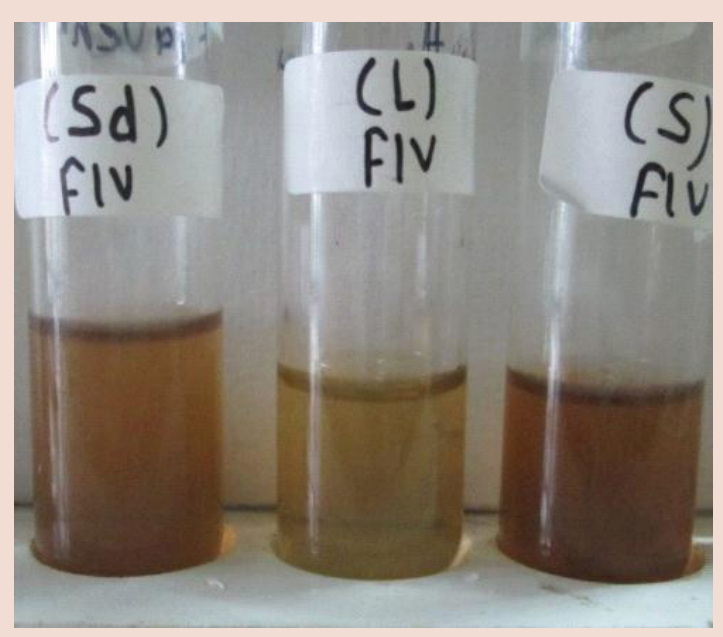

Figure 2: Flavonoid analysis of aqueous extract of shoot, leaf and seed of $N$. arbor-tristis

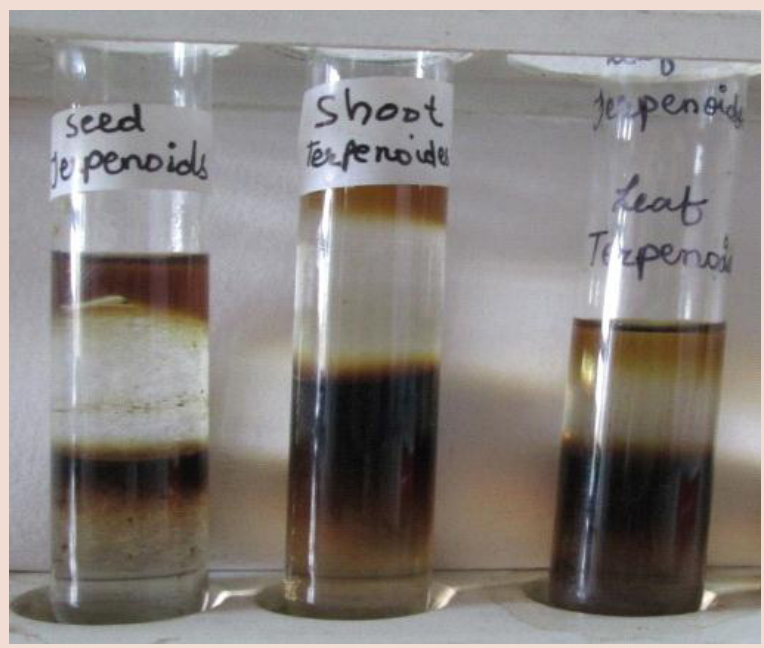

Figure 3: Terpenoid analysis of aqueous extract of shoot, leaf and seed of N. arbor-tristis

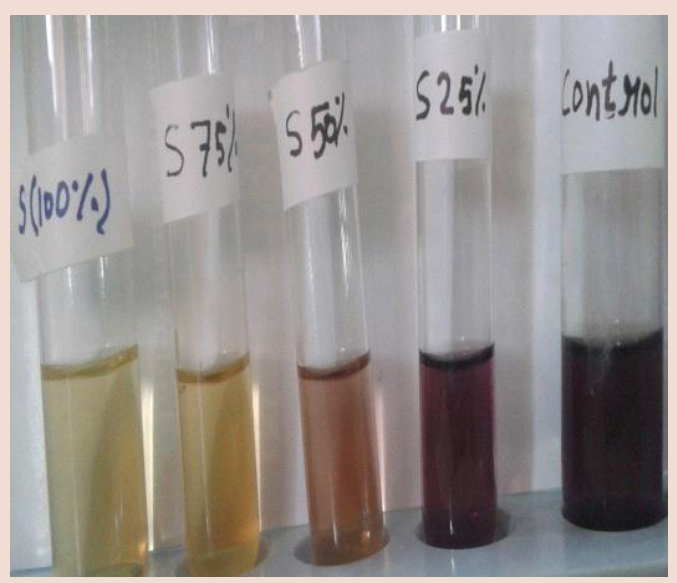

Figure 4: Antioxidant activity of different concentrations of ethanol extract of shoot of $\mathrm{N}$. arbor-tristis

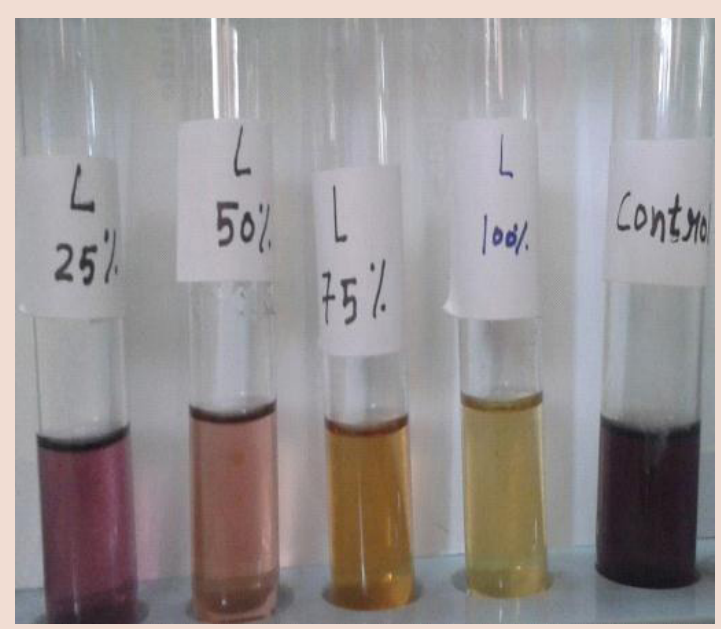

Figure 5: Antioxidant activity of different concentrations of ethanol extract of leaf of $N$. arbor-tristis

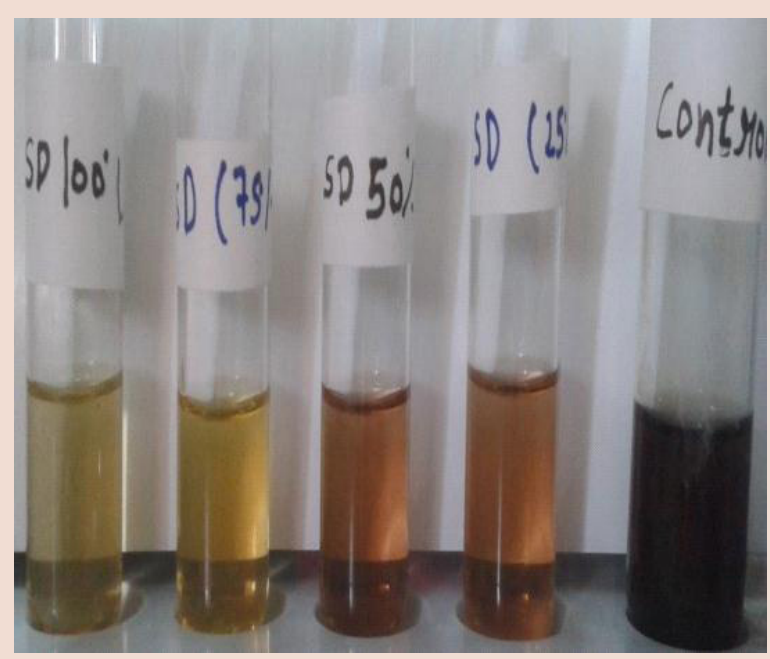

Figure 6: Antioxidant activity of different concentrations of ethanol extract of seed of $N$. arbor-tristis 
aqueous and ethanol extract. The work may suggest the application of leaf and shoot and seed of $N$. arbor-tristis in the area of pharmaceutics. It may prove a milestone for further research in this field.

\section{CONCLUSION}

This study established a fact that the plant N. arbor-tristis is a good source of antioxidant compounds and different plant organs responded differently regarding the nature of solvent used to extract the metabolites from them.

\section{ACKNOWLEDGEMENT}

The authors acknowledge Department of Science \& Technology, Government of India for funding the research through research project vide reference no. SR/WOS-A/LS-514/2013 under Women Scientist Scheme to carry out this work. The authors also thankful the Principal St. Aloysius College [autonomous] Cantt, Jabalpur, India for providing the necessary facilities for the research.

\section{CONFLICT OF INTEREST}

The author declare no conflict of interest.

\section{ABBREVIATION USED}

AA: Antioxidant activity; DPPH: 2, 2-Diphenyl -1-picryhydrazyl; mM: Mili molar.

\section{REFERENCES}

1. Aliyu AB, Ibrahim MA, Ibrahim H, Musa AM, Lawal AY, Oshanimi JA, et al. Free radical scavenging and total antioxidant capacity of methanol extract of Ethuliaconyzoides growing in Nigeria. Roman biotech letters. 2012;17(4):7458-65.

2. Hayat K, Zhange X, Farooq U, Abbas S, Xia S, Jia C, et al. Effect of microwave treatment on phenolic content and antioxidant activity of citrus mandarin pomace. Food Chem. 2010;123(2):423-9.

3. Anagnostopoulou MA, Kefalas P, Papageorgiou VP Assimepoulou AN and BoskouD. Radical scavenging activity of various extract and fractions of sweet orange peel. Food Chem. 2006:94(1):19-25.
4. Raghavendra M, Reddy AM, Yadav PR, Sudharshan RA, Siva K. Comparative studies on the in vitro antioxidant properties of methenolic leafy extracts from six edible leafy vegetables of India. Asian J Pharmaceutic Clinicl Res. 2013; 6(3): $96-9$

5. Mishima S, Matsumoto K, Futamura Y. Antitumor effect of stilbenoids from Vateria indica against allografted sarcoma s-180 in animal model. J Experimen therapeutic oncol. 2003;3(5):283-8.

6. Gupta M, Mazumber UK, Kumar UK and Kumar TS. Antitumor activity and antioxidant role of Bauhinia racemosa against Enrlich ascites carcinoma in swiss albino mice, Acta Pharmacol Sinica. 2004;25(8):1070-6.

7. Gul MZ, Ahmad F, Kondapi AK, Qureshi IA, Ghazi IA. Antioxidant and antiproliferative activities of Abrusprecatorius leaf extracts-an in vitro study. BMC Complementary and Alternative Medicine. 2013;13(1):53.

8. Thangavelu NR, Thomas S. In vitro antioxidant studies on ethenolic extract of leaves and stems of Nyctanthes arbor-tristis $L$ (night flowering jasmine). Int $J$ Biol Med Res. 2010;1(4):188-92.

9. Javanmardi J, Stushnoff C, Locke E, Vivanco JM. Antioxidant activity and total phenolic content of Iranian Ocimum accessions. Food Chem. 2003:83(4): 547-50.

10. Sofowora A. Medicinal plants and traditional in Africa. Spectrum Books. Ibadan 1993: 150

11. Trease GE and Evan WC. Pharmacognosy, Bailliere Tindall, London. 1989; Edition13:176-80

12. Mensor VL, Fabio SM, Gildor GL, Alexander SR, Tereza CD, Cintia SC, et al. Screening of Brazilian plant extracts for antioxidant activity by the use of DPPH free radical methods. Phytothe Res. 2001;15(2):127-30.

13. Chouhan A, Gokhale M, Bansal S. Antimicrobial potential of Nyctanthes arbortristis and isolation of Colletotrichum gleosporioides-an endophyte. J Pharm Res. 2014;8(8):1082-90

14. Yadav RNS, Agarwala M. Phytochemical analysis of some medicinal plants J Phytol. 2011;3(12):10-4.

15. Chew AL, Jessica JJ, Sasidharan S. Antioxidant and antibacterial activity of different parts of Leucasaspera. Asian Pac J Trop Biomed. 2012;2(3):176-80.

16. Sharma S, Ahmed A, Gupta S. Phytochemical and antioxidant activity of ethenolic bark extract of Nyctanthes arbor-tristis Linn. Innovat Pharmaceutic Pharmacother. 2001;1(3):177-84

17. Saxena RS, Gupta B, Lata S. Tranquilizing, antihistaminic and purgative activity of Nyctanthes arbortristis leaf extract. J Ethanopharmcol. 2002:81(3):321-5

18. Sasmal D, Das S, Basu SP. Phytoconstituents and therapeutic potential of Nyctanthes arbor-tristis Linn. Pharmacognosy reviews. 2007:1(2):344-9.

19. Pandey RS. Antioxidant activity of Nyctanthes arbor-tristis. Asian J Pharmac Life Sci. 2012;2(2):360-4.

\section{PICTORIAL ABSTRACT}

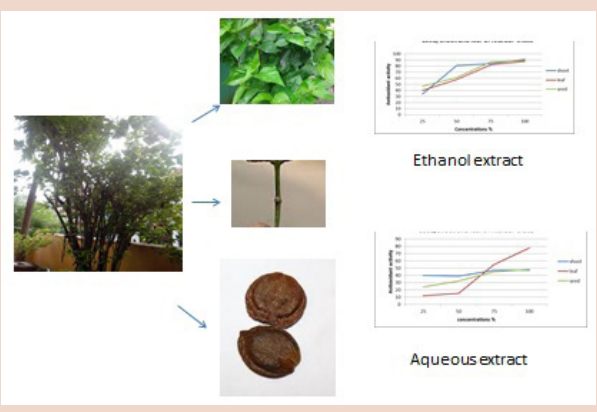

\section{SUMMARY}

- Phytochemical (terpenoids, anthraquinone, flavonoids) and antioxidant activity was analyzed for aqueous and ethanolic extracts of shoot, leaf and seeds of Nyctanthes arbor- tristis (Linn).

- Antioxidant activity of both extracts was analyzed for their different concentrations $(25,50,75$ and 100). Antioxidant activity increased with increasing concentration of both plant extract.

- Ethanol extract of shoot revealed more activity than seed and leaf of $N$. arbor-tristis.

- Among the all lowest concentrations the maximum antioxidant activity was recorded on lowest concentration (25\%) in seed ethanolic extract.

- In aqueous extracts the leaf extract showed more antioxidant activity than shoot and seed. Aqueous extract of seed has the minimum antioxidant activity.

\section{ABOUT AUTHORS}

Saraswati Patel: Is a post graduate student at the Department of Botany \& Microbiology, St. Aloysius College, Jabalpur-M.P., India. She graduated in Bachelor of Microbiology from Government Model Science College, Jabalpur, M.P. Her Dissertation was focused on the "Antioxidant activity of different parts of and antibacterial activity of secondary metabolites from endophytic fungi of Nyctanthes arbor-tristis linn."

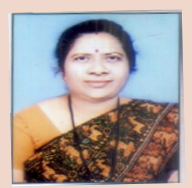

Dr. (Mrs.) Mamta Gokhale: Is an DST (Department of Science \& Technology, New Delhi) project fellow at St. Aloysius (autonomous) College, Jabalpur-M.P. She received her Ph.D. from Rani Durgawati University, JabalpurM.P. At present she is working on plant tissue culture, studies on secondary metabolites \& endophytic fungi. She has published 18 papers \& participated various National \& International Conferences. 